\title{
Research on Sports Record Management Application Development \& Uses in Mobile Environment
}

\author{
Seongwon Seo \\ Global Instituted For Talented Education, \\ KAIST (Korea Advanced Institute of Science and Technology), Daejeon, South Korea \\ Semin Kim and Choong Ho Lee \\ Dept. of Information \& Communication Engineering, \\ Hanbat University, Daejeon, South Korea
}

\begin{abstract}
In this research, mobile application for sports activity record management was designed and developed. Due to appearance of smart phone and IoT, using Android mobile system is more suitable than PC with Windows OS, widely used in pro-sports environment, in students' school sports environment. Two teams for volleyball, basketball, and football were liaised respectively to experiment mobile application developed in this research. Teams were divided into one that uses the application, and the other who does not. Motivation, psychological satisfaction, training accomplishment and etc. were analyzed. As a result, differences in effect of mobile application according to character of each sports.
\end{abstract}

Keywords - Application for education, Mobile Application

\section{INTRODUCTION}

Republic of Korea accomplished outstanding results in many global contests recently, thus remarkable development was made superficially. Sport stars shining in foreign major leagues are being produced. Excellent results in major contest such as the Summer \& Winter Olympics, Premiere 12, World Baseball Classic, FIFA World Cup, and etc. promoted Korea to the world $[1,2]$. However, there were countless sacrifices of students of athletic clubs to the other side of this development,

In most of the areas, basic fundamental education provided in school was ignored and students were merely treated as "sports machine", resulting in malformed development [3].

As a result, many students in Korea did not get proper education. of course, harsh life waited for students who could not become the famous sports star.

Polices that educate students so that 「Studying Athlete」could be produced came out as the countermeasure for this issue. Normalization of school PE and weekend leagues were carried out. This made a trend of students both studying and training.

This is to help students choose other future when sport does not work out well.

Charles Minlend used to be pharmacist before he came to KBL, and P. Pareto, the gold medalist are great examples of it. Other than these two, there are many students both studying and training in overseas.

Nevertheless, this is a great burden for coaches of athletic club in reality. Although school education should be guaranteed, but for the coaches of the club, they have to supervise the club so that students could win various contests to get into college [4]. To lighten the burden of these coaches, development of efficient educational method that helps students maximize their training hours is needed. Also, sports might have various characteristics.

Therefore, 'Game Records Management' mobile application is expected to contribute a lot to efficient time using and training for students. 


\section{RELATED RESEARCHES}

\section{A. Examples of applying mobile device in sport or physical education}

HaTaeHeyon(2012)developed a mobile application for use of basketball clubs. He mainly researched on digitalized record management application. Application above is a system that records data of score, rebound, assist, and etc. into numbers. Data analyzed through the application were shown after the game to athletes, and effects on motivations were analyzed. Through these results, effective time managing, and training method were proposed to the basketball club [5].

ChoWookSang(2016)researched on mobile methods for assessments in school PE textbooks. Based on this, possibility of proper assessment was investigated. It proposed a possibility of improvement of both PE teacher's professionality and work efficiency when PE teacher and all the students possess the mobile apparatus with appropriate mobile application [6].

KimSemin(2016)developed a mobile application that records location information for basketball club. This application figures out the route of assist and score, making tactics visual. As a result, effectively studying tactics and enhancement of exercise effect were possible [1].

Previous researches are tended to limit to basketball. It is quite rare to find the research on various sports. However, because every sport has distinctive characteristics (number of people, budget support, growth system, popularity and etc.), comparative study among sports are needed.

As above researches suggest, our research enhances motivation of athletes, and developed a mobile application to help with effective training and to measure the effect.

\section{B. Examples of applying similar system in Korea's field of sports}

In Korea's field of sports, professional man \& woman basketball and volleyball use record management system. As shown in Figure 1 and 2, record management system is an actual softer used in Korean Basketball League [4, 7]. It works on Windows OS based PC. Two PCs are for inputting data and one PC is connected in RS-232c serial communication to manage the data. However, the system above is the appropriate for school athletic club and the below are the reasons why.

First, above system is managed by league's professionals, not by club's coaching staff. Also, in pro-sports club there are up to ten coaching staffs. Whereas, there are less than three coaching staffs in school club for most of the time.

Second, other than few number of staff members, there's a high possibility that those coaches of athletic club do not have the ability to use the computer system and the network system. After all, they are also the product of malformed education system, not getting the basic education while they were students themselves.

Third, a lot of money is required to use many Windows OS based PCs, and more money is needed to recruit professionals to manage the system. Most of the time, there is budget runs short $[8,9]$.

According to reasons stated above, using mobile apparatus to manage the records are favorable in school. Reasons supporting are as follows.

First, mobile device is comparatively cheaper that Windows OS based PC.

Second, most of the people possess mobile device, and it does not need extra cost to use.

Third, education enhancing computer and network system utilization ability is required for using the programs installed in Windows OS based PC. On the other hand, most people can skillfully used mobile device, meaning no extra education is needed.

Fourth, in order to use Windows OS based PC, specific skill of connecting and managing several PCs in a network is needed. Whereas LTE or Wifi are all that's needed for mobile devices.

Fifth, programs for Windows OS based PC are quite complicated due to many functions using diverse inputting functions such as keyboards and mouse. However, mobile device has smaller screen and fewer ways to input data, making it have only the essential functions. This rather provides advantage of simple and easy usage.

This research focuses on developing a mobile application for easy management that does not require extra cost. 


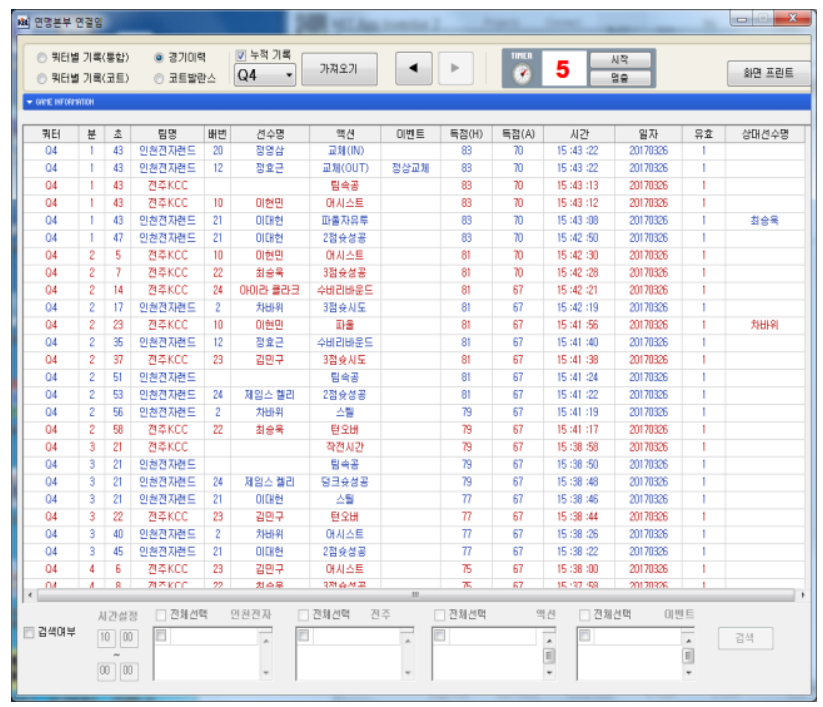

Figure 1. . Part of record management system used in KBL

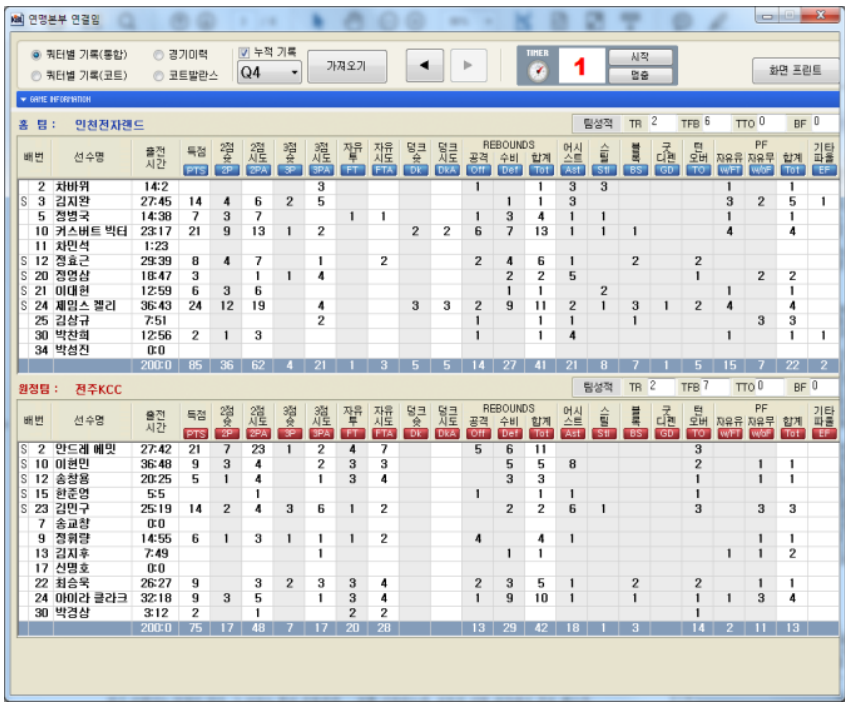

Figure 2. . Part of data digitized from record management system used in $\mathrm{KBL}$

\section{MOBILE APPLICATION DEVELOPMENT FOR EACH SPORT}

This research developed a mobile application for each sport. Only the essential parts were established according to characteristics of each sports. It does have a common factor of outputting "game record" in character string on the data showing screen by combining data, time and etc. Characteristics of each sports are as follows.

\section{A. Mobile application for basketball club}

Figure 3 shows a mobile application for basketball. It has a function that controls the match time. This is for ball leaving the court, and frequent fouls due to frequent physical strife. Also, success and failure of shooting is a very important part. Other than that, it still has lots of important data to be recorded and fast data inputting is needed. When all the time passes Init. button is activated, allowing setting the time back to 10:00. Since offensive rebound or defensive rebound happen after the failure of scoring, succeed to scoring (1P, 2P, 3P) and failure to scoring (1PA, 2PA, 3PA) buttons are prepared. Basketball has various records such as block, steal, foul and etc. and putting all the data into the small screen is not possible. Therefore, only the important records like score, rebound, assist and etc. are shown. 


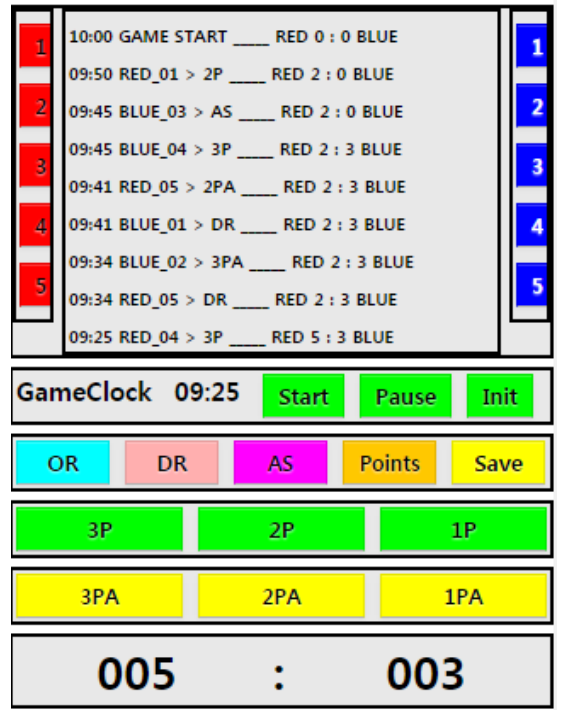

Figure 3. Screenshot of mobile application's 'game record management' for basketball

\section{B. Mobile application for volleyball club}

Figure 4 shows a mobile application for volleyball. Unlike the basketball or football application, it does not show the match time. It is because volleyball is a sport that sets certain amount of score, not time. Not only score of the current set but set score is also important. Therefore, part that shows the score contains a button to raise the set score. The function of organizing the records when either side earns set score of 3, and starting a new game is added.

\section{Mobile application for Football club}

Figure 5 shows the mobile application of football. Just like the basketball application, it has function that controls match time. Most of the parts are plain, but showing all eleven players vertical array due to small screen is a difficult part in developing. This was covered by the scroll function, but this resulted in slower data input.

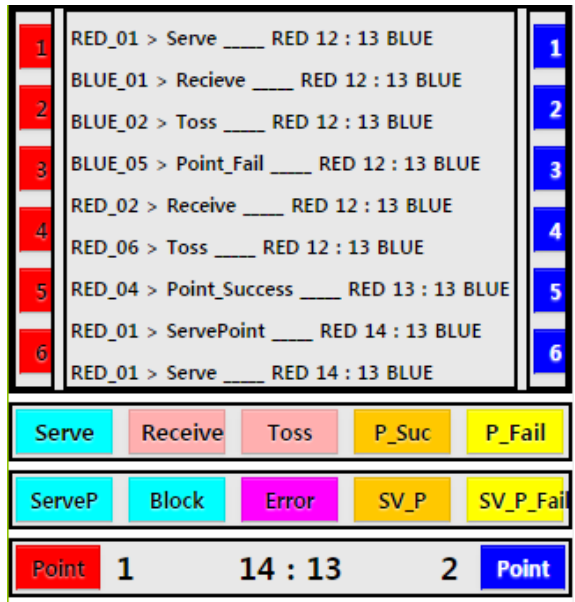

Figure 4. Screenshot of mobile application's 'game record management' for volleyball 


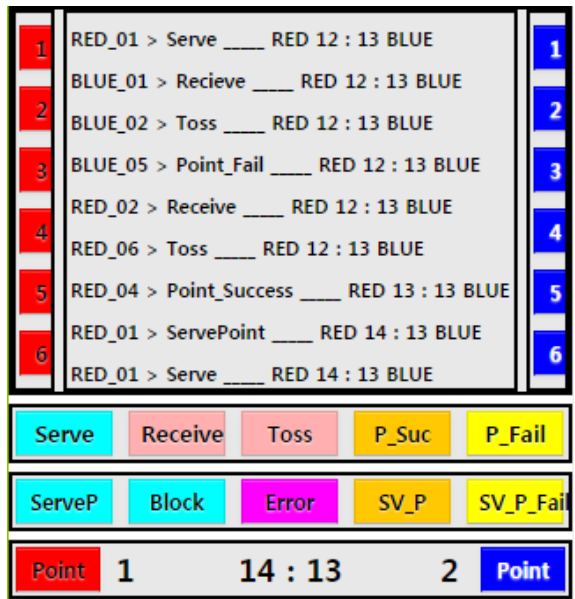

Figure 5. Screenshot of mobile application's 'game record management' for volleyball

\section{APPLICATION}

\section{A. Subject of experiment and limited matter}

Athletic clubs participated in this research are from middle school. Team A did not use the mobile application but Team B did. Personnel setup is shown in Table 1.

Table -1 Personnel setup

\begin{tabular}{c|cc|cc}
\hline & \multicolumn{2}{|c|}{ Team A } & \multicolumn{2}{c}{ Team B } \\
\hline & Coach & Player & Coach & Player \\
\hline Basketball & 1 & 10 & 1 & 11 \\
\hline Volleyball & 1 & 13 & 1 & 12 \\
\hline Football & 2 & 22 & 2 & 22 \\
\hline
\end{tabular}

All the club coaches of volleyball, basketball, and football possess Android OS based smart phone, and most players also use Android OS. The cheap price of Android smart phone played a big role. iOS based application was not developed since iOS users were only one or two for each sport. iOS users shared other players' smart phone to see the record. In Team B, coaches personally inputted the data and checked the data with the cooperation from research assistant. Since the number of coaches form each club is small, quality assessment was done catechistically. Survey was given to the players

\section{B. Motivation}

Athletic clubs participated in this research are from middle school. Team A did not use the mobile application but Team B did. Personnel setup is shown in Table 1.

- Coaches of Team A: "No general answer since it was the same as always"

- Basketball Coach of Team B: "Got a thought of checking the records more carefully"

- Volleyball Coach of Team B: "Got a thought of checking the flow of the match through the game records"

- Football Coach of Team B: "Usually it was hard quantify percentage of ball possession. But with the application's help I tried to quantify the records."

Coaches of Team A did not really have any other idea, since it was same as always. On the other hand, coaches of Team B showed strong desire to analyze the match with the game record data.

For the results of athletes' motivation, Team B showed more motivation in all the categories as shown in Table 1. Many athletes from Team B commented that they had to give more care since they could see their records. 
Table -2 Motivation

\begin{tabular}{|c|c|c|c|c|c|c|c|}
\hline Category & Team & $5 \mathrm{pt}$. & 4 pt. & 3 pt. & $2 \mathrm{pt}$. & $1 \mathrm{pt}$. & Avg. \\
\hline \multirow{6}{*}{$\begin{array}{l}\text { Got more motivation than usual to raise the } \\
\text { record in the next game } \\
\text { (usual: before the research test) }\end{array}$} & Basketball A & 1 & 4 & 5 & 0 & 0 & 3.60 \\
\hline & Basketball B & 3 & 6 & 2 & 0 & 0 & 4.09 \\
\hline & Volleyball A & 1 & 6 & 5 & 1 & 0 & 3.54 \\
\hline & Volleyball B & 2 & 7 & 2 & 0 & 0 & 4.00 \\
\hline & Football A & 4 & 10 & 7 & 1 & 0 & 3.77 \\
\hline & Football B & 6 & 11 & 5 & 0 & 0 & 4.05 \\
\hline \multirow{6}{*}{$\begin{array}{l}\text { Got motivation to train more to do better in the } \\
\text { next game. }\end{array}$} & Basketball A & 1 & 5 & 4 & 0 & 0 & 3.70 \\
\hline & Basketball B & 4 & 6 & 1 & 0 & 0 & 4.27 \\
\hline & Volleyball A & 1 & 7 & 5 & 0 & 0 & 3.69 \\
\hline & Volleyball B & 2 & 9 & 1 & 0 & 0 & 4.08 \\
\hline & Football A & 4 & 9 & 7 & 2 & 0 & 3.68 \\
\hline & Football B & 6 & 10 & 6 & 0 & 0 & 4.00 \\
\hline
\end{tabular}

\section{Satisfaction level}

- $\quad$ Coaches of Team A: No general answer since it was the same as always

- Basketball Coach of Team B: Very satisfied with recording the flow of the match, But smart phone is too small for containing all the important records. Tablet PC should be fit for the job.

- Volleyball Coach of Team B: Due to many players, inputting the data is quite busy. Still very satisfied with seeing athlete's objective ability.

- Football Coach of Team B: It is not easy to input all the athletes. Since football does not score a lot unlike other sports, not a lot shows directly, leading to loss of interest.

Sports that need lots of data, basketball and volleyball, showed great satisfaction with the fact that they could retrace and analyze the game. However coaches pointed out that there are more important records to be inputted. Football coaches commented that it looked a bit simple since information about pass took most of the part.

Team B athletes generally showed higher satisfaction with the training. However, football athletes did not show great difference. Football athletes commented that everyone knows who scored without using the application. Most of the record it provided was number of passes, therefore the satisfaction was not great. Basketball and volleyball athletes commented that analyzing their own records and comparing with rival athletes enhanced the interest in training.

Since Team A did not use the application, survey on mobile application performance satisfaction was only done be Team B.

Table -3 Satisfaction

\begin{tabular}{l|l|c|c|c|c|c|c}
\hline Category & Team & $5 \mathrm{pt}$. & $4 \mathrm{pt}$. & $3 \mathrm{pt}$. & $2 \mathrm{pt}$. & $1 \mathrm{pt}$. & Avg. \\
\hline \multirow{2}{*}{$\begin{array}{l}\text { Got more motivation than usual to } \\
\text { raise the record in the next game } \\
\text { (usual: before the research test) }\end{array}$} & Basketball A & 1 & 4 & 5 & 0 & 0 & 3.60 \\
\cline { 2 - 8 } & Basketball B & 3 & 6 & 2 & 0 & 0 & 4.09 \\
\cline { 2 - 9 } & Volleyball A & 1 & 6 & 5 & 1 & 0 & 3.54 \\
\cline { 2 - 9 } & Volleyball B & 2 & 7 & 2 & 0 & 0 & 4.00 \\
\cline { 2 - 9 } & Football A & 4 & 10 & 7 & 1 & 0 & 3.77 \\
\cline { 2 - 9 } & Football B & 6 & 11 & 5 & 0 & 0 & 4.05 \\
\hline \multirow{2}{*}{$\begin{array}{l}\text { Got motivation to train more to do } \\
\text { better in the next game. }\end{array}$} & Basketball A & 1 & 5 & 4 & 0 & 0 & 3.70 \\
\cline { 2 - 9 } & Basketball B & 4 & 6 & 1 & 0 & 0 & 4.27 \\
\cline { 2 - 9 } & Volleyball A & 1 & 7 & 5 & 0 & 0 & 3.69 \\
\hline
\end{tabular}




\begin{tabular}{|c|c|c|c|c|c|c}
\hline Volleyball B & 2 & 9 & 1 & 0 & 0 & 4.08 \\
\hline Football A & 4 & 9 & 7 & 2 & 0 & 3.68 \\
\hline Football B & 6 & 10 & 6 & 0 & 0 & 4.00 \\
\hline
\end{tabular}

\section{Training accomplishment}

Training accomplishment is independent of athlete's personal satisfaction. It is what coaches think. Each coach graded their own athletes. There was no significant difference in athlete's motor ability. Basketball and volleyball might show a bit of difference, but sports ability does not improve significantly in a day. However, the ability to read the flow of the game improved after using the mobile application. It is an effect of tracing all the records given by the application.

Table -4 Training accomplishment

\begin{tabular}{c|c|c|c|c|c|c|c}
\hline Category & Team & 5 pt. & 4 pt. & 3 pt. & 2 pt. & 1 pt. & Avg. \\
\hline \multirow{4}{*}{$\begin{array}{l}\text { Did athlete's movement improve } \\
\text { in the training? }\end{array}$} & Basketball A & 3 & 4 & 3 & 0 & 0 & 4.00 \\
\cline { 2 - 8 } & Basketball B & 4 & 5 & 2 & 0 & 0 & 4.18 \\
\cline { 2 - 8 } & Volleyball A & 4 & 6 & 3 & 0 & 0 & 4.08 \\
\cline { 2 - 8 } & Volleyball B & 5 & 7 & 0 & 0 & 0 & 4.42 \\
\cline { 2 - 8 } & Football A & 5 & 11 & 6 & 0 & 0 & 3.95 \\
\cline { 2 - 8 } & Football B & 5 & 11 & 6 & 0 & 0 & 3.95 \\
\hline \multirow{4}{*}{$\begin{array}{l}\text { Did understanding of tactics and } \\
\text { improve? }\end{array}$} & Basketball A & 0 & 7 & 3 & 0 & 0 & 3.70 \\
\cline { 2 - 8 } & Basketball B & 2 & 8 & 1 & 0 & 0 & 4.09 \\
\cline { 2 - 8 } & Volleyball A & 0 & 6 & 7 & 0 & 0 & 3.46 \\
\cline { 2 - 8 } & Volleyball B & 1 & 10 & 1 & 0 & 0 & 4.00 \\
\cline { 2 - 8 } & Football A & 0 & 8 & 14 & 0 & 0 & 3.36 \\
\cline { 2 - 8 } & Football B & 2 & 14 & 6 & 0 & 0 & 3.82 \\
\hline
\end{tabular}

Training accomplishment is independent of athlete's personal satisfaction. It is what coaches think. Each coach graded their own athletes. There was no significant difference in athlete's motor ability. Basketball and volleyball might show a bit of difference, but sports ability does not improve significantly in a day. However, the ability to read the flow of the game improved after using the mobile application. It is an effect of tracing all the records given by the application.

\section{CONCLUSIONS AND RECOMMENDATIONS}

Mobile application developed in this research put a goal of maximizing the efficiency of training for student athletes with limited training hour. Therefore enhancing the motivation and the satisfaction of training with the help of the mobile application. Coaches can manage student athletes' ability and use the mobile application to enhance athletes' understanding of tactics. The results of this research are as follows.

First, mobile application with more diverse sports than pervious was developed.

Second, Therefore for students who have do both studying and training, this application will provide a great deal of advantage.

Assignments following this research are as follow.

First, since it's only limited to certain ball games, more developing is needed for many other sports. 
Second, a measure for covering the shortcoming of mobile device's small screen has to be found. Small screen cannot contain all the functions.

\section{REFERENCES}

[1] S.M. Kim, C.S. Ryu and K.S. You: "A Design and Implementation of Mobile 'Moving Data' Coaching Application for Training in the Athletic Club", Journal of the Korea Institute of Information and Communication Engineering, Vol. 20, No. 8, pp.1511-1516 (2016)

[2] D. H. Lee, "Exploring Desirable Direction of School Athletic Teams as a Education Setting", Korean Society for the Study of Physical Education, vol. 17, no. 1, pp. 1-16, (2012)

[3] K.H. Jin : "A Study on the Improvement and Effects of Policy for the Studying Soccer Student Players", Ph.D. Thesis, Changwon National University (2010)

[4] I. H. Kim and K. S. Cho: "The Relationship between Role Stress and Job Burnout of School Athletic Supervisors and Stress Coping Strategy", Journal of Korean Society for the Study of Physical, vol. 15, no. 1, pp. 371-384 (2010)

[5] T. H. Ha and S. M. Kim: "Design and Implementation of Smart phone-based Records Management Application for Sports Clubs" , Journal of Digital Convergence, vol. 10, no.11, pp. 395-402 (2012)

[6] O. S. Cho and J. W. Kim, "A Possibility of School Physical Education Assessment Utilizing Mobile Devices", The Korea Journal of Sports Science, vol. 25, no. 1, pp. $905-914$ (2016)

[7] Korea Basketball League(KBL). Sports2I KBL Statistics Application Download Page. [Internet]. Available: http://kbl.or.kr/ down/publish.htm/.

[8] E. Bryan Carne, A Professional's Guide to Data Communication in a TCP/IP World, London: Artech House (2004)

[9] M. vans, J. Noble and J. Hochenbaum, "Arduino in Action”, New York, NY: Manning Publications, (2013)

[1] R. Mehul, "Discrete Wavelet Transform Based Multiple Watermarking Scheme", in Proceedings of the 2003 IEEE TENCON, pp. 935-938, 2003. 